\title{
Review
}

\section{Mitochondria Dysfunction and Neurodegenerative Disorders: Cause or Consequence}

\author{
Vanessa A. Morais ${ }^{\mathrm{a}, \mathrm{b}, *}$ and Bart De Stroopera,b \\ ${ }^{a}$ Center for Human Genetics, K.U. Leuven, Leuven, Belgium \\ ${ }^{\mathrm{b}}$ Department of Molecular and Developmental Genetics, VIB, Leuven, Belgium
}

Accepted 7 April 2010

\begin{abstract}
Mitochondria are crucial regulators of energy metabolism and apoptotic pathways and have been closely linked to the pathogenesis of neurodegenerative disorders. In this review we mainly focus on mitochondrial dysfunction in two of the most prevalent neurological disorders: Alzheimer's disease and Parkinson's disease. We discuss whether the role of mitochondria in those diseases should be considered primordial or secondary to other processes that eventually lead to neurodegeneration. In the case of Parkinson's disease, the role of mitochondria is quite clear and might be involved in the mechanism of this disorder. For Alzheimer's disease, the evidence in favor of such a link is more indirect, and mitochondrial dysfunction likely occurs at a later stage of the disorder.
\end{abstract}

Keywords: Alzheimer's disease, apoptosis, mitochondria, oxidative stress, Parkinson's disease

\section{INTRODUCTION}

For many years, mitochondria were commonly believed to transmit hereditary information. Only from the 1950s onwards, when a method for isolating intact mitochondria was developed, the modern understanding of mitochondrial function was founded. Mitochondria are now considered essential organelles for life and death of a cell. They not only participate in energy conversion via oxidative phosphorylation, but also have major roles in many cellular functions, including inter-

* Correspondence to: Vanessa Morais, PhD, VIB Department of Molecular and Developmental Genetics, Laboratory for the Research of Neurodegenerative Diseases, K.U. Leuven - Onderwijs en Navorsing $1,6^{\circ}$ verd., Campus Gasthuisberg, Herestraat 49, bus 602, 3000 Leuven, Belgium. Tel.: +32 16 346371; Fax: +32 16 347181; E-mail: Vanessa.Morais@cme.vib-kuleuven.be. mediary metabolism, calcium buffering, regulation of signal cascades, and apoptosis regulation [1]. The development of powerful technologies, such as live-cell imaging, 3D reconstruction, and electron tomography has overruled the conventional static image of mitochondria and revealed that mitochondria are extremely dynamic organelles capable of establishing an interconnected network regulated by fusion/fission processes (reviewed in [2]). Constant shape remodeling and subcellular trafficking of these organelles depend on the microtubules network and on motor proteins. Consequently, mitochondria may be organized into lengthy traveling chains, packed tightly into relatively stable groups, or appear in many other formations based upon the particular needs of the cell and the characteristics of its microtubular network [3]. The structure of the mitochondria is intrinsically interwoven with the performance of the organelle. Mitochondria have a dou- 
ble membrane that divides the organelle into a narrow intermembrane space (IMS) and a much larger internal matrix, each of which contains highly specialized proteins. The outer membrane of mitochondria contains voltage-dependent anion channels that in turn make the membrane permeable to metabolites and small peptides (3000 Da). Similarly, the inner membrane, which is highly convoluted so that a large number of invaginations called cristae are formed, also forms a barrier for most molecules thus preventing their passage. For this, the inner membrane utilizes a group of transport proteins, the TOM/TIM protein complexes (reviewed in [4]). The mitochondrial respiratory chain is located within the inner membrane, and here oxidative phosphorylation (OXPHOS) occurs. The respiratory chain or electron transport chain (ETC) is composed by Complex I (NADH ubiquinone oxidoreductase), II (succinate ubiquinone oxidoreductase), III (ubiquinonecytochrome $\mathrm{c}$ reductase), and IV (cytochrome oxidase) and by the $\mathrm{F}_{1} \mathrm{~F}_{0}$-ATP synthase, also known as complex $\mathrm{V}$ [1]. In a nutshell, the transport of electrons down the ETC releases favorable energy that is used by Complex I, III, and IV to pump protons from the matrix side across the inner membrane, thus creating a proton gradient (basic inside) and an electrochemical gradient (negative inside) across the IMS. This gradient is known as the mitochondrial membrane potential and is used to drive phosphorylation of ADP to ATP (ATP production) by $\mathrm{F}_{1} \mathrm{~F}_{0}$-ATP synthase.

Albeit due to high energy demands or due to increased sensitivity to apoptosis and reactive oxygen species (ROS) production, mitochondrial diseases preferentially seem to affect only a subset of tissues, most notably muscles and neurons. In the latter, mitochondrial dysfunction leads to neurodegenerative disorders. Mitochondrial DNA (mtDNA) mutations, mutations in nuclear-encoded mitochondrial proteins, or mutated proteins localized in multiple intracellular compartments can affect mitochondrial function in those diseases (reviewed in [5]).

For several decades, mitochondrial dysfunction has also been linked to the two most abundant neurodegenerative disorders, e.g., Alzheimer's and Parkinson's diseases. In this review, we address to what extent mitochondria are directly involved in the pathogenesis of these disorders; also, to what extent this dysfunction represents an epiphenomenon of the cell death and neuronal loss accompanying these diseases, and finally the potential role of mitochondrial dysfunction as key amplifiers of the disease process.

\section{MITOCHONDRIAL DYSFUNCTION IN ALZHEIMER'S DISEASE}

Alzheimer's disease (AD) is a devastating neurological disorder clinically characterized by impairment of cognitive function and changes in behavior and personality. Morphological hallmarks of the pathology are cortical and hippocampal atrophy, accumulation of neurofibrillary tangles mainly composed of hyperphosphorylated forms of the microtubular protein tau, and the presence of senile plaques. The major component of these plaques is the amyloid- $\beta$ peptide $(\mathrm{A} \beta)$ in two most abundant forms, $\mathrm{A} \beta_{40}$ and $\mathrm{A} \beta_{42}$.

\section{$A \beta$ affects mitochondrial enzymes}

There is accumulating evidence from in vitro, in vivo, and human pathological tissue studies suggesting that mitochondrial abnormalities are a common event in AD. Electron microscopy analysis of mitochondria in various regions of AD brain revealed significant morphological alterations [6]. In situ hybridization to mitochondrial DNA, immunocytochemistry of cytochrome c oxidase, and electron micrographs of brain biopsies confirmed that mitochondrial abnormalities were present in AD cases [7,8]. These studies also showed that neurons presenting increased oxidative damage in AD had increased levels of mitochondrial DNA and cytochrome c oxidase in the cytosol, which correlated with the significantly reduced number of mitochondria in these tissues. In some AD cases, the decreased cytochrome c oxidase activity was accompanied by increased free-radical generation and reduced energy metabolism $[6,9,10]$. Analysis of isolated mitochondria from AD platelets showed a decrease in cytochrome c oxidase activity and in ATP levels, while an increase in ROS was observed [11]. In addition, a decrease in mitochondrial membrane potential and reduced levels of ATP were also observed in neurons from an amyloid- $\beta$ protein precursor $(\mathrm{A} \beta \mathrm{PP})$ transgenic mouse model [12]. These results indicated mitochondrial energy metabolism impairment, and since this transgenic mouse model did not reveal plaque deposition, the authors postulated a major role for intracellular $\mathrm{A} \beta$ in the observed mitochondrial dysfunction. Studies performed in PC12 and NT2 cells incubated with $\mathrm{A} \beta_{25-35}$ and $\mathrm{A} \beta_{1-42}$ peptides displayed reduced activity of the respiratory chain [13-15], and $\mathrm{A} \beta$ appears to inhibit key mitochondrial enzymes in the brain and in isolated mitochondria, especially cytochrome $c$ oxidase [16-18]. Decreased activity of 
these mitochondrial enzymes impair electron transport, ATP production, oxygen consumption, and mitochondrial membrane potential, leading to an increase in oxidative stress, release of cytochrome $c$, and finally apoptosis. However, these studies do not provide any insight in how $\mathrm{A} \beta$ might cause those impairments and it is not clear to what extent these observations are also valid for what occurs in the brain of patients.

\section{A $\beta$ interacts with mitochondrial proteins}

Recent studies triggered by the finding that $\mathrm{A} \beta$ peptides inhibit mitochondrial respiration by causing opening of the permeability transition pore (PTP) $[19,20]$, suggested that $\mathrm{A} \beta$ directly interacts with cyclophilin D (CypD), a PTP component that binds cyclosporine $A$ and renders the channels more sensitive to $\mathrm{Ca}^{2+}$. This could theoretically provide a molecular basis for a pathogenic mechanism linking $\mathrm{A} \beta$ to mitochondria [21]. Unfortunately, the authors did not provide an answer to the question how $\mathrm{A} \beta$ would be able to reach the mitochondria, as $\mathrm{A} \beta$ is generated in the lumen of the secretory and recycling pathways and at the cell surface.

Additionally, a yeast two-hybrid screen identified the $\mathrm{A} \beta$-binding alcohol dehydrogenase (ABAD), which is a member of the short chain dehydrogenase/reductase [22]. This interaction was validated by co-immunoprecipitation studies performed in AD patient brains and in a transgenic mouse model overexpressing $\mathrm{A} \beta \mathrm{PP} / \mathrm{ABAD}$, which also manifested elevated levels of oxidative stress and impaired memory [23]. In additional overexpression studies, the interaction of $\mathrm{A} \beta$ with ABAD caused mitochondrial oxidative damage, increased carbonylation of mitochondrial proteins, and impaired activity of respiratory complexes [24]. Again, although intriguing, it remains to be confirmed that this interaction also occurs at the physiological level of protein expression and is indeed required for modulation of ABAD activity. Nevertheless, the origin of mitochondrial $A \beta$ is still a matter of debate. Studies that have attempted to address this question revealed that in vitro import of $\mathrm{A} \beta_{1-40}$ and $\mathrm{A} \beta_{1-42}$ in isolated rat mitochondria occurs via the mitochondrial TOM machinery [25].

HtrA2/Omi, a pro-apoptotic serine protease that is released to the cytoplasm from the mitochondria upon apoptotic stimuli [26], is another mitochondrial protein that has been identified to interact with $\mathrm{A} \beta$ [27]. Overexpression studies have shown that $\mathrm{A} \beta$ binds to the PZD domain of HtrA2/Omi and can co-immunoprecipitate the cytosolic form of HtrA2/Omi. It is not clear whether this interaction occurs within the mitochondria or after apoptotic stimuli have caused the release of the cytosolic form of HtrA2/Omi from the mitochondria. It has also been reported that intra-mitochondrial $\mathrm{A} \beta$ blocks the entry of nuclear-encoded proteins into mitochondria, leading to decreased mitochondrial membrane potential, increased ROS production, oxygen glucose deprivation, and altered mitochondrial morphology [28].

\section{$A \beta$ affects mitochondria morphology and transport}

Another possible pathway to explain the link between $\mathrm{A} \beta$ and mitochondrial dysfunction is the possibility that increased ROS production activates the mitochondrial fission proteins Drp1 and Fis1, which cause mitochondrial fragmentation [29]. Mitochondrial fragmentation is observed in AD brain and can indeed be explained by oxidation of Drp-1. The latter would also lead to synapse loss [30]. Additional studies have implied a role of $\mathrm{A} \beta$ in modulating proteins involved in the mitochondrial fission/fusion processes as well. Overexpression of wild-type or Swedish A $\beta$ PP mutant form in human neuroblastoma M17 cells show significantly decreased levels of Drp-1 and OPA1, whereas Fis1 levels were significantly upregulated [31]. Notably, overexpression of Drp-1 in these cells rescued abnormal mitochondrial distribution, while overexpression of OPA1 rescued mitochondrial fragmentation. Additional studies in hippocampal tissues of AD patients showed reduced levels of Drp-1, OPA1, Mfn1, and Mfn2, and increased levels of Fis1 [32].

$\mathrm{A} \beta$ has also been reported to affect axonal transport of mitochondria. Recent studies in a Drosophila model for AD revealed depletion of presynaptic mitochondria, decreased transport of axonal mitochondria, and decreased number of synaptic vesicles $[33,34]$. These studies suggested that $\mathrm{A} \beta$ accumulation depletes presynaptic mitochondria, and that this event preceded the change in axonal transport of mitochondria. Embryonic hippocampal neurons from rat treated with $\mathrm{A} \beta$ indeed showed rapid and severe impairment of mitochondrial transport [35], further supporting the idea that $\mathrm{A} \beta$ can impair mitochondrial transport and consequently contributes to synaptic dysfunction. Apparently the effects of $\mathrm{A} \beta$ on mitochondrial function are pleiotropic and can be caused by effects on the axonal transport machinery or on the mitochondrial fission/fusion machinery. Besides $\mathrm{A} \beta$-mitochondrial induced toxicity, a few reports have also linked tau protein to mitochondria dysfunction. A triple tau/A $\beta \mathrm{PP} /$ presenilin 
transgenic AD mouse model showed disturbed mitochondrial membrane potential and defects in the electron transport chain, as well as an increase in oxidative stress [36]. Transport of mitochondria along the axons was disturbed in the presence of isoform 3 and 4 of tau [37]. It is generally thought that the hyperphosphorylated form of tau causes toxicity in AD brain. Some reports suggest that reduced mitochondrial energy levels cause hyperphosphorylation and consequent aggregation of tau $[38,39]$.

\section{Is $A \beta$ processed in the mitochondria?}

As indicated already, it remains unclear to what extent the different proposed mechanisms really contribute to the pathogenesis of $\mathrm{AD}$ in patients. A major problem is the lack of a good model to explain how $\mathrm{A} \beta$ enters the mitochondria. Some studies have suggested that its precursor $\mathrm{A} \beta \mathrm{PP}$ can be processed within the mitochondria. A mitochondrial presequence-like targeting sequence found behind the endoplasmatic targeting sequence has been identified in $\mathrm{A} \beta \mathrm{PP}$ and appeared to be able to guide, under certain conditions, $\mathrm{A} \beta \mathrm{PP}$ to the mitochondria [40]. In addition, ectopically expressed wild-type or AD-linked Swedish A $\beta$ PP mutants have also been found to localize to mitochondria in different cell types. Recent studies have identified active $\gamma$ secretase complex within the inner mitochondrial membrane, containing all four members of the complex PS, NCT, Aph-1, and Pen2 [41,42]. It should be noticed that most studies locate the $\gamma$-secretase in the membranes of organelles along the biosynthetic pathway, and more work is needed to exclude the possibility that part of the signals reflected contamination of vesicular structures in the mitochondrial preparations (it is notoriously difficult to separate mitochondria completely from ER). An additional problem is the question how $\gamma$-secretase mediated cleavage of $\mathrm{A} \beta \mathrm{PP}$ could occur in the mitochondria [40]. More precise work is needed to precisely localize $\mathrm{A} \beta \mathrm{PP}$ and $\gamma$-secretase and to demonstrate that protease and substrate are located in the same membrane and that their topology is compatible with $\gamma$-secretase processing of $\mathrm{A} \beta \mathrm{PP}$. This, along with the fact that no reports have verified the presence of functional $\beta$-secretase in this organelle, makes that at this moment one would be inclined to conclude that the observed mitochondrial toxicity caused by $\mathrm{A} \beta$ is likely indirect.

Also for the other reports related to $\mathrm{A} \beta$ associated mitochondrial toxicity, a major question remains to be addressed: the origin of the intracellular cytoplasmic
$\mathrm{A} \beta$. Thus, while the available evidence clearly shows that $\mathrm{A} \beta$ can affect mitochondrial function, the major question on how importantly the described mechanisms contribute to sporadic AD in the real patient still requires further investigation.

\section{MITOCHONDRIAL DYSFUNCTION IN PARKINSON'S DISEASE}

Parkinson's disease (PD) is a chronic progressive neurodegenerative movement disorder with a prevalence of $1.8 \%$ in individuals of 65 years and older [43]. PD is clinically characterized by motor impairments involving resting tremor, progressive rigidity, bradykinesia, and postural instability. PD pathology is characterized most prominently by loss of dopaminergic neurons in the substantia nigra pars compacta and in most cases by the formation of intraneuronal protein aggregates called Lewy bodies [44]. At the time of clinical presentation, approximately $50-70 \%$ of the dopaminergic neurons have been lost [45] and surviving neurons may present Lewy body inclusions.

\section{Mitochondria in sporadic PD}

In contrast to $\mathrm{AD}$, the involvement of mitochondrial dysfunction in PD, as a direct causal factor, is reasonably well supported by observations in patients. In fact, mitochondrial involvement in PD has been postulated for many years based on observations with mitochondrial toxins, which appear to cause in human beings and experimental animals Parkinson's like syndromes. For instance, MPTP (1-methyl 4-phenyl1,2,3,6-tetrahydropyridine) produced PD-like symptoms in designer drug abusers [46]. Its metabolite $\mathrm{MPP}^{+}$is actively transported into dopaminergic neurons by the dopamine transporter. Within these neurons, $\mathrm{MPP}^{+}$enters the mitochondria and selectively inhibits the mitochondrial respiratory chain Complex I of the ETC [47]. Additionally, exposure to rotenone, a highly selective mitochondrial Complex I inhibitor, also reproduced behavioral and neuropathological features of PD in rats. Brain samples of PD patients were shown to display a mild defect of Complex I [48]. The mechanism of Complex I inhibition toxicity probably involves mitochondrial-induced oxidative stress, caused by the block of the mitochondrial respiratory chain [49]. Oxidative stress is the result of an imbalance between excessive production of ROS and limited antioxidant defenses. Mitochondria generate most of 
the ROS as a byproduct of oxidative phosphorylation. Nevertheless, the selective vulnerability of dopaminergic neurons to mitochondrial dysfunction remains elusive.

\section{Mitochondria and familial PD}

The recent identification of genes involved in the pathogenesis of familial forms of PD further suggests that at least a subgroup of what is called PD, could be caused by primary deficits in mitochondrial function [50]. PD mutations have been reported to occur in genes encoding for $\alpha$-synuclein, DJ-1, Leucin RichRepeat Kinase (LRRK2), ubiquitin C-terminal hydrolase L1 (UCHL1), phosphatase-tensin homologue (PTEN)-induced kinase 1 (PINK1), and Parkin, as well as within the mtDNA. Mutations in the gene encoding the mitochondrial serine protease HtrA2/Omi have also been linked to PD in several families [51-53]. Some of the genes are directly involved in mitochondrial function (and dysfunction) whereas for other genes, such as LRRK2, the link is at best indirect. We discuss some salient features of the different proteins encoded by the PD genes with regard to their possible effects on mitochondrial function.

Mutations in $\alpha$-synuclein, the major component of Lewy bodies, cause autosomal dominant familial PD. Recent studies have revealed that $\alpha$-synuclein appears to contain an amino-terminal mitochondrial targeting sequence [54] and acidification of the cytosol or overexpression of $\alpha$-synuclein itself can cause localization of the protein to mitochondria [55,56]. Additionally, $\alpha$ synuclein-null mice demonstrate increased resistance to MPTP [57], whereas transgenic $\alpha$-synuclein animal models treated with MPTP present swollen, morphological abnormal mitochondria [58]. Additionally, small oligomers of $\alpha$-synuclein can lead to $\mathrm{Ca}^{2+}$ dysregulation, and calpain, a major $\mathrm{Ca}^{2+}$-activated protease, can cleave $\alpha$-synuclein producing a truncated form which is prone to aggregate, thus leading to formation of fibrils [59]. Overall, these observations suggest that $\mathrm{Ca}^{2+}$ dysregulation and consequent fibril aggregation could eventually lead to alterations in the mitochondrial PTP. The PTP complex can undergo a $\mathrm{Ca}^{2+}$-triggered conformational change that can lead to the opening of the mitochondrial PTP, causing mitochondrial swelling and consequent rupture of the outer membrane allowing $\mathrm{Ca}^{2+}$ to leave the mitochondria placing further stress on nearby mitochondria. The release of cell death mediators and the increased production of ROS consequently lead to neuronal cell death.

\section{PINK1 and Parkin affect mitochondria function}

The most convincing evidence for the involvement of mitochondrial dysfunction are the mutations in the mitochondrial serine/threonine kinase PINK1 (PTENinduced putative kinase 1) that cause recessive hereditary PD in several families [60,61]. PINK1 is a highly conserved protein, containing a catalytic serine/threonine kinase domain, ubiquitously expressed in the human brain. The PINK1 kinase not only presents a mitochondrial targeting sequence, but has actually also been shown directly to localize to the mitochondria [62]. Down regulation of PINK1 expression in SH-SY5Y decreased cell viability and increased apoptosis [63]. Studies performed in Drosophila pinkl mutants resulted in loss of dopaminergic neurons, including shortened lifespan, apoptotic muscle degeneration, and male sterility [64-66]. Additionally, studies in Drosophila and in HeLa cells indicated that Pinkl deficiency leads to altered mitochondrial morphology [64-68]. Pink1 deficient mice reveal impaired dopamine release [69], deficient mitochondrial respiration, and increased sensitivity to oxidative stress and to induced cytochrome $c$ release [70,71], while overexpression and loss of function studies suggested an antiapoptotic activity for PINK1 [63,72,73]. PD-related mutations and an artificial kinase-dead mutant abolish this anti-apoptotic effect [72]. One could argue that PINK1 most probably exerts its neuroprotective effect by phosphorylating specific mitochondrial proteins. This argument was validated by the identification of three PINK1 mitochondrial substrates, i.e., the mitochondrial heat shock protein TRAP1, the proapoptotic protein $\mathrm{Htr} 2 \mathrm{a} / \mathrm{OMI}$ [74,75], and, more recently, Parkin [76]. PINK1 has also been shown to associate with Hsp90/Cdc37 chaperones [77,78]. Evidence that pink1 genetically interacts with the fission/fusion machinery of mitochondria has supported the hypothesis that PINK1 deficiency affects various mitochondrial functions via interference with mitochondrial dynamics $[79,80]$. It should be noticed however that genetic interactions between pinkl and drpl (dynamin related protein) or fis1, genes implicated in mitochondrial fission [81], do not imply necessarily that pinkl is in the same molecular pathway as these proteins. Interestingly, mutant PINK1 has been shown to exacerbate mitochondrial alterations by disturbing the mitochondrial $\mathrm{Ca}^{2+}$ fluxes, action that is promoted by mutant $\alpha-$ synuclein, thus suggesting a cooperative role of these two proteins [82]. An appealing finding that could explain most of the observations is the fact that the ab- 
sence of PINK1 leads to decreased enzymatic activity of Complex I [71]. The energy deficiency caused by this defect leads, in Drosophila neurons, to altered synaptic function. This is reflected in deficient mobilization of the reserve pool of synaptic vesicles during rapid stimulation. This deficit can be rescued by adding ATP to the synapse, confirming an energy deficit at the level of the synapse. Loss of Complex I would result in the reduction of the mitochondrial electrochemical gradient, and therefore promote the opening of the voltage dependent PTP, which can in turn cause increased cytochrome $c$ release and cell death [83]. Reduced Complex I activity can also lead to increased levels of ROS production as found in several studies [84,85]. Loss of Complex I in synaptic mitochondria also results in impaired ATP production, which apparently underlies the reserve pool mobilization defects during intense stimulation of the synapse [71]. Consistent with this hypothesis is the fact that ATP levels in pink1 mutant flies are reduced compared to controls [64], providing an explanation for the neuronal defects in pinkl mutants.

The ubiquitously expressed Parkin, an E3 ubiquitin ligase, is another gene implicated in autosomal recessive PD [86]. Parkin-null mice and Parkin Drosophila mutants develop apoptotic muscle degeneration with mitochondrial pathology and decreased resistance to oxidative stress [87-89]. Reduced levels of mitochondrial proteins involved in mitochondrial oxidative phosphorylation were reported in Parkin-knockout mice, which exhibited normal brain morphology, but increased striatal extracellular dopamine levels [87]. Overexpression of Parkin in cultured cells prevents mitochondrial swelling and stress-induced apoptosis. Despite the fact that the majority of Parkin is localized to the cytosol, as the majority of the E3 ligases, some Parkin was suggested to be localized in the mitochondrial matrix, where it would enhance mitochondrial gene transcription and biogenesis in proliferating cells $[90,91]$. The exact mechanism for the protective function of Parkin in mitochondria remains unknown. Similar to PINK1 mutant flies, Drosophila Parkin mutants exhibited reduced lifespan, locomotor defects resulting from apoptotic muscle degeneration and mitochondrial structural alterations [88]. Additionally, overexpression of Parkin in PC12 cells protected against ceramide-mediated cell death by delaying mitochondrial swelling and subsequent cytochrome $c$ release and caspase 3 activation, and this protective effect was abrogated by Parkin mutants [92]. Overexpression of Parkin was shown to rescue the mitochondria dysfunction caused by PINK1 deficiency, suggesting that the two proteins could cooperate, probably by regulating the balance between mitochondrial fission and fusion, hence preserving mitochondrial integrity in various stress conditions $[66,80]$. Furthermore, in a recent study it was shown that Parkin is involved in autophagy of dysfunctional mitochondria [93], which might provide a mechanistic explanation for the genetic interaction that has been reported between Parkin and Pink1 in Drosophila [64,66,68], further reinforcing the concept that Parkin has a neuroprotective role. A working hypothesis that has emerged recently is that Parkin and PINK1 act together as a "mitochondrial quality control machinery", to modulate the trafficking of defective mitochondria to the lysosome-rich perinuclear area [94]. In brief, the loss of mitochondrial membrane potential causes cytosolic Parkin to be recruited to mitochondria, and this recruitment occurs in a PINK1-mediated fashion. The tubular mitochondrial network collapses and aggregated mitochondria clusters become surrounded with autophagic vacuoles. Although Parkin genetically interacts with PINK1, Parkin-dependent ubiquitination of PINK1 or PINK1-phosphorylation of Parkin has not yet been established in this working model.

\section{CONCLUSION/PERSPECTIVES}

For PD, the connection between mitochondrial dysfunction and pathology is quite strong, especially because genetic mutations in mitochondrial proteins are causally involved in at least some forms of PD. For AD, the situation is clearly much more complicated. Nevertheless, while it is not possible to draw conclusions as to whether mitochondrial dysfunction is a potential direct pathogenic cause of certain forms of $\mathrm{AD}$, one can probably safely agree that mitochondrial dysfunction does occur at some point during the disease.

\section{ACKNOWLEDGMENTS}

This work was supported by the Fund for Scientific Research Flanders; KULeuven; Federal Office for Scientific Affairs Belgium (IUAP P6/43/), a Methusalem grant of the Flemish Government, VIB. VAM is a Fundacao para a Ciencia e Tecnologia (FCT, Portugal) postdoctoral researcher.

Authors' disclosures available online (http://www.jalz.com/disclosures/view.php?id=405). 


\section{REFERENCES}

[1] Nicholls D (2002) Mitochondrial bioenergetics, aging, and aging-related disease. Sci Aging Knowledge Environ 2002, pe12.

[2] Wasilewski M, Scorrano L (2009) The changing shape of mitochondrial apoptosis. Trends Endocrinol Metab 20, 287-294.

[3] Dimmer KS, Scorrano L (2006) (De)constructing mitochondria: what for? Physiology (Bethesda) 21, 233-241.

[4] Bolender N, Sickmann A, Wagner R, Meisinger C, Pfanner N (2008) Multiple pathways for sorting mitochondrial precursor proteins. EMBO Rep 9, 42-49.

[5] Kwong JQ, Beal MF, Manfredi G (2006) The role of mitochondria in inherited neurodegenerative diseases. J Neurochem $\mathbf{9 7}$, 1659-1675.

[6] Baloyannis SJ (2006) Mitochondrial alterations in Alzheimer's disease. J Alzheimers Dis 9, 119-126.

[7] Hirai K, Aliev G, Nunomura A, Fujioka H, Russell RL, Atwood CS, Johnson AB, Kress Y, Vinters HV, Tabaton M, Shimohama S, Cash AD, Siedlak SL, Harris PL, Jones PK, Petersen RB, Perry G, Smith MA (2001) Mitochondrial abnormalities in Alzheimer's disease. J Neurosci 21, 3017-3023.

[8] Castellani R, Hirai K, Aliev G, Drew KL, Nunomura A, Takeda A, Cash AD, Obrenovich ME, Perry G, Smith MA (2002) Role of mitochondrial dysfunction in Alzheimer's disease. $J$ Neurosci Res 70, 357-360.

[9] Nunomura A, Perry G, Aliev G, Hirai K, Takeda A, Balraj EK, Jones PK, Ghanbari H, Wataya T, Shimohama S, Chiba S, Atwood CS, Petersen RB, Smith MA (2001) Oxidative damage is the earliest event in Alzheimer disease. J Neuropathol Exp Neurol 60, 759-767.

[10] Lin MT, Beal MF (2006) Alzheimer's APP mangles mitochondria. Nat Med 12, 1241-1243.

[11] Cardoso SM, Proenca MT, Santos S, Santana I, Oliveira CR (2004) Cytochrome c oxidase is decreased in Alzheimer's disease platelets. Neurobiol Aging 25, 105-110.

[12] Keil U, Bonert A, Marques CA, Strosznajder JB, Muller-Spahn F, Muller WE, Eckert A (2004) Elevated nitric oxide production mediates beta-amyloid-induced mitochondria failure. Pol J Pharmacol 56, 631-634.

[13] Pereira C, Santos MS, Oliveira C (1999) Involvement of oxidative stress on the impairment of energy metabolism induced by A beta peptides on PC12 cells: protection by antioxidants. Neurobiol Dis 6, 209-219.

[14] Pereira C, Santos MS, Oliveira C (1998) Mitochondrial function impairment induced by amyloid beta-peptide on PC12 cells. Neuroreport 9, 1749-1755.

[15] Cardoso SM, Santos S, Swerdlow RH, Oliveira CR (2001) Functional mitochondria are required for amyloid betamediated neurotoxicity. FASEB J 15, 1439-1441.

[16] Hauptmann S, Keil U, Scherping I, Bonert A, Eckert A, Muller WE (2006) Mitochondrial dysfunction in sporadic and genetic Alzheimer's disease. Exp Gerontol 41, 668-673.

[17] Reddy PH, Beal MF (2008) Amyloid beta, mitochondrial dysfunction and synaptic damage: implications for cognitive decline in aging and Alzheimer's disease. Trends Mol Med 14, 45-53.

[18] Caspersen C, Wang N, Yao J, Sosunov A, Chen X, Lustbader JW, Xu HW, Stern D, McKhann G, Yan SD (2005) Mitochondrial Abeta: a potential focal point for neuronal metabolic dysfunction in Alzheimer's disease. FASEB J 19, 2040-2041.

[19] Casley CS, Canevari L, Land JM, Clark JB, Sharpe MA (2002) Beta-amyloid inhibits integrated mitochondrial respiration and key enzyme activities. J Neurochem 80, 91-100.
[20] Casley CS, Land JM, Sharpe MA, Clark JB, Duchen MR, Canevari L (2002) Beta-amyloid fragment 25-35 causes mitochondrial dysfunction in primary cortical neurons. Neurobiol Dis 10, 258-267.

[21] Du H, Guo L, Fang F, Chen D, Sosunov AA, McKhann GM, Yan Y, Wang C, Zhang H, Molkentin JD, Gunn-Moore FJ, Vonsattel JP, Arancio O, Chen JX, Yan SD (2008) Cyclophilin $\mathrm{D}$ deficiency attenuates mitochondrial and neuronal perturbation and ameliorates learning and memory in Alzheimer's disease. Nat Med 14, 1097-1105.

[22] Yan SD, Fu J, Soto C, Chen X, Zhu H, Al-Mohanna F, Collison K, Zhu A, Stern E, Saido T, Tohyama M, Ogawa S, Roher A, Stern D (1997) An intracellular protein that binds amyloid-beta peptide and mediates neurotoxicity in Alzheimer's disease. Nature 389, 689-695.

[23] Lustbader JW, Cirilli M, Lin C, Xu HW, Takuma K, Wang N, Caspersen C, Chen X, Pollak S, Chaney M, Trinchese F, Liu S, Gunn-Moore F, Lue LF, Walker DG, Kuppusamy P, Zewier ZL, Arancio O, Stern D, Yan SS, Wu H (2004) ABAD directly links Abeta to mitochondrial toxicity in Alzheimer's disease. Science 304, 448-452.

[24] Manczak M, Anekonda TS, Henson E, Park BS, Quinn J, Reddy PH (2006) Mitochondria are a direct site of A beta accumulation in Alzheimer's disease neurons: implications for free radical generation and oxidative damage in disease progression. Hum Mol Genet 15, 1437-1449.

[25] Hansson Petersen CA, Alikhani N, Behbahani H, Wiehager B, Pavlov PF, Alafuzoff I, Leinonen V, Ito A, Winblad B, Glaser E, Ankarcrona M (2008) The amyloid beta-peptide is imported into mitochondria via the TOM import machinery and localized to mitochondrial cristae. Proc Natl Acad Sci U $S$ A 105, 13145-13150.

[26] Lindholm D, Eriksson O, Korhonen L (2004) Mitochondrial proteins in neuronal degeneration. Biochem Biophys Res Commun 321, 753-758.

[27] Park HJ, Seong YM, Choi JY, Kang S, Rhim H (2004) Alzheimer's disease-associated amyloid beta interacts with the human serine protease HtrA2/Omi. Neurosci Lett 357, 63-67.

[28] Sirk D, Zhu Z, Wadia JS, Shulyakova N, Phan N, Fong J, Mills LR (2007) Chronic exposure to sub-lethal beta-amyloid (Abeta) inhibits the import of nuclear-encoded proteins to mitochondria in differentiated PC12 cells. J Neurochem $\mathbf{1 0 3}$, 1989-2003.

[29] Barsoum MJ, Yuan H, Gerencser AA, Liot G, Kushnareva Y, Graber S, Kovacs I, Lee WD, Waggoner J, Cui J, White AD, Bossy B, Martinou JC, Youle RJ, Lipton SA, Ellisman MH, Perkins GA, Bossy-Wetzel E (2006) Nitric oxide-induced mitochondrial fission is regulated by dynamin-related GTPases in neurons. EMBO J 25, 3900-3911.

[30] Cho DH, Nakamura T, Fang J, Cieplak P, Godzik A, Gu Z, Lipton SA (2009) S-nitrosylation of Drp1 mediates beta-amyloidrelated mitochondrial fission and neuronal injury. Science 324, 102-105.

[31] Wang X, Su B, Siedlak SL, Moreira PI, Fujioka H, Wang Y, Casadesus G, Zhu X (2008) Amyloid-beta overproduction causes abnormal mitochondrial dynamics via differential modulation of mitochondrial fission/fusion proteins. Proc Natl Acad Sci U S A 105, 19318-19323.

[32] Wang X, Su B, Lee HG, Li X, Perry G, Smith MA, Zhu X (2009) Impaired balance of mitochondrial fission and fusion in Alzheimer's disease. J Neurosci 29, 9090-9103.

[33] Zhao XL, Wang WA, Tan JX, Huang JK, Zhang X, Zhang BZ, Wang YH, YangCheng HY, Zhu HL, Sun XJ, Huang FD Expression of beta-amyloid Induced age-dependent presynaptic 
and axonal changes in Drosophila. J Neurosci 30, 1512-1522.

[34] Iijima-Ando K, Hearn SA, Shenton C, Gatt A, Zhao L, Iijima K (2009) Mitochondrial mislocalization underlies Abeta42induced neuronal dysfunction in a Drosophila model of Alzheimer's disease. PLOS ONE 4, e8310.

[35] Rui Y, Tiwari P, Xie Z, Zheng JQ (2006) Acute impairment of mitochondrial trafficking by beta-amyloid peptides in hippocampal neurons. J Neurosci 26, 10480-10487.

[36] Rhein V, Song X, Wiesner A, Ittner LM, Baysang G, Meier F, Ozmen L, Bluethmann H, Drose S, Brandt U, Savaskan E, Czech C, Gotz J, Eckert A (2009) Amyloid-beta and tau synergistically impair the oxidative phosphorylation system in triple transgenic Alzheimer's disease mice. Proc Natl Acad Sci U S A 106, 20057-20062.

[37] Stoothoff W, Jones PB, Spires-Jones TL, Joyner D, Chhabra E, Bercury K, Fan Z, Xie H, Bacskai B, Edd J, Irimia D, Hyman BT (2009) Differential effect of three-repeat and fourrepeat tau on mitochondrial axonal transport. J Neurochem 111, 417-427.

[38] Swerdlow RH, Khan SM (2004) A "mitochondrial cascade hypothesis" for sporadic Alzheimer's disease. Med Hypotheses 63, 8-20.

[39] Escobar-Khondiker M, Hollerhage M, Muriel MP, Champy P, Bach A, Depienne C, Respondek G, Yamada ES, Lannuzel A, Yagi T, Hirsch EC, Oertel WH, Jacob R, Michel PP, Ruberg M, Hoglinger GU (2007) Annonacin, a natural mitochondrial complex I inhibitor, causes tau pathology in cultured neurons. J Neurosci 27, 7827-7837.

[40] Anandatheerthavarada HK, Biswas G, Robin MA, Avadhani NG (2003) Mitochondrial targeting and a novel transmembrane arrest of Alzheimer's amyloid precursor protein impairs mitochondrial function in neuronal cells. J Cell Biol 161, 4154.

[41] Hansson CA, Frykman S, Farmery MR, Tjernberg LO, Nilsberth C, Pursglove SE, Ito A, Winblad B, Cowburn RF, Thyberg J, Ankarcrona M (2004) Nicastrin, presenilin, APH-1, and PEN-2 form active gamma-secretase complexes in mitochondria. J Biol Chem 279, 51654-51660.

[42] Ankarcrona M, Hultenby K (2002) Presenilin-1 is located in rat mitochondria. Biochem Biophys Res Commun 295, 766770 .

[43] de Rijk MC, Launer LJ, Berger K, Breteler MM, Dartigues JF, Baldereschi M, Fratiglioni L, Lobo A, Martinez-Lage J, Trenkwalder C, Hofman A (2000) Prevalence of Parkinson's disease in Europe: A collaborative study of population-based cohorts. Neurologic Diseases in the Elderly Research Group. Neurology 54, S21-23.

[44] Braak H, Ghebremedhin E, Rub U, Bratzke H, Del Tredici $\mathrm{K}$ (2004) Stages in the development of Parkinson's diseaserelated pathology. Cell Tissue Res 318, 121-134.

[45] Orth M, Schapira AH (2002) Mitochondrial involvement in Parkinson's disease. Neurochem Int 40, 533-541.

[46] Langston JW, Ballard PA, Jr. (1983) Parkinson's disease in a chemist working with 1-methyl-4-phenyl-1,2,5,6tetrahydropyridine. $N$ Engl J Med 309, 310.

[47] Krueger MJ, Singer TP, Casida JE, Ramsay RR (1990) Evidence that the blockade of mitochondrial respiration by the neurotoxin 1-methyl-4-phenylpyridinium (MPP+) involves binding at the same site as the respiratory inhibitor, rotenone. Biochem Biophys Res Commun 169, 123-128.

[48] Panov A, Dikalov S, Shalbuyeva N, Taylor G, Sherer T, Greenamyre JT (2005) Rotenone model of Parkinson disease: multiple brain mitochondria dysfunctions after short term systemic rotenone intoxication. J Biol Chem 280, 42026-42035.
[49] Greenamyre JT, Sherer TB, Betarbet R, Panov AV (2001) Complex I and Parkinson's disease. IUBMB Life 52, 135-141.

[50] Schapira AH (2008) Mitochondria in the aetiology and pathogenesis of Parkinson's disease. Lancet Neurol 7, 97-109.

[51] Bogaerts V, Theuns J, van Broeckhoven C (2008) Genetic findings in Parkinson's disease and translation into treatment: a leading role for mitochondria? Genes Brain Behav 7, 129151.

[52] Bogaerts V, Nuytemans K, Reumers J, Pals P, Engelborghs S, Pickut B, Corsmit E, Peeters K, Schymkowitz J, De Deyn PP, Cras P, Rousseau F, Theuns J, Van Broeckhoven C (2008) Genetic variability in the mitochondrial serine protease HTRA2 contributes to risk for Parkinson disease. Hum Mutat 29, 832840.

[53] Mandemakers W, Morais VA, De Strooper B (2007) A cell biological perspective on mitochondrial dysfunction in Parkinson disease and other neurodegenerative diseases. J Cell Sci 120, 1707-1716.

[54] Devi L, Raghavendran V, Prabhu BM, Avadhani NG, Anandatheerthavarada HK (2008) Mitochondrial import and accumulation of alpha-synuclein impair complex I in human dopaminergic neuronal cultures and Parkinson disease brain. J Biol Chem 283, 9089-9100.

[55] Cole NB, Dieuliis D, Leo P, Mitchell DC, Nussbaum RL (2008) Mitochondrial translocation of alpha-synuclein is promoted by intracellular acidification. Exp Cell Res 314, 20762089.

[56] Shavali S, Brown-Borg HM, Ebadi M, Porter J (2008) Mitochondrial localization of alpha-synuclein protein in alphasynuclein overexpressing cells. Neurosci Lett 439, 125-128.

[57] Dauer W, Przedborski S (2003) Parkinson's disease: mechanisms and models. Neuron 39, 889-909.

[58] Song DD, Shults CW, Sisk A, Rockenstein E, Masliah E (2004) Enhanced substantia nigra mitochondrial pathology in human alpha-synuclein transgenic mice after treatment with MPTP. Exp Neurol 186, 158-172.

[59] Dufty BM, Warner LR, Hou ST, Jiang SX, Gomez-Isla T, Leenhouts KM, Oxford JT, Feany MB, Masliah E, Rohn TT (2007) Calpain-cleavage of alpha-synuclein: connecting proteolytic processing to disease-linked aggregation. Am J Pathol 170, 1725-1738.

[60] Silvestri L, Caputo V, Bellacchio E, Atorino L, Dallapiccola B, Valente EM, Casari G (2005) Mitochondrial import and enzymatic activity of PINK1 mutants associated to recessive parkinsonism. Hum Mol Genet 14, 3477-3492.

[61] Beilina A, Van Der Brug M, Ahmad R, Kesavapany S, Miller DW, Petsko GA, Cookson MR (2005) Mutations in PTENinduced putative kinase 1 associated with recessive parkinsonism have differential effects on protein stability. Proc Natl Acad Sci U S A 102, 5703-5708.

[62] Gandhi S, Muqit MM, Stanyer L, Healy DG, Abou-Sleiman PM, Hargreaves I, Heales S, Ganguly M, Parsons L, Lees AJ, Latchman DS, Holton JL, Wood NW, Revesz T (2006) PINK1 protein in normal human brain and Parkinson's disease. Brain 129, 1720-1731.

[63] Deng H, Jankovic J, Guo Y, Xie W, Le W (2005) Small interfering RNA targeting the PINK1 induces apoptosis in dopaminergic cells SH-SY5Y. Biochem Biophys Res Commun 337, 1133-1138.

[64] Clark IE, Dodson MW, Jiang C, Cao JH, Huh JR, Seol JH, Yoo SJ, Hay BA, Guo M (2006) Drosophila pink1 is required for mitochondrial function and interacts genetically with parkin. Nature 441, 1162-1166.

[65] Park J, Lee SB, Lee S, Kim Y, Song S, Kim S, Bae E, Kim J, 
Shong M, Kim JM, Chung J (2006) Mitochondrial dysfunction in Drosophila PINK1 mutants is complemented by parkin. Nature 441, 1157-1161.

[66] Yang Y, Gehrke S, Imai Y, Huang Z, Ouyang Y, Wang JW, Yang L, Beal MF, Vogel H, Lu B (2006) Mitochondrial pathology and muscle and dopaminergic neuron degeneration caused by inactivation of Drosophila Pink1 is rescued by Parkin. Proc Natl Acad Sci U S A 103, 10793-10798.

[67] Exner N, Treske B, Paquet D, Holmstrom K, Schiesling C, Gispert S, Carballo-Carbajal I, Berg D, Hoepken HH, Gasser T, Kruger R, Winklhofer KF, Vogel F, Reichert AS, Auburger G, Kahle PJ, Schmid B, Haass C (2007) Loss-of-function of human PINK1 results in mitochondrial pathology and can be rescued by parkin. $J$ Neurosci $\mathbf{2 7}, 12413-12418$.

[68] Poole AC, Thomas RE, Andrews LA, McBride HM, Whitworth AJ, Pallanck LJ (2008) The PINK1/Parkin pathway regulates mitochondrial morphology. Proc Natl Acad Sci U S A 105, 1638-1643.

[69] Kitada T, Pisani A, Porter DR, Yamaguchi H, Tscherter A, Martella G, Bonsi P, Zhang C, Pothos EN, Shen J (2007) Impaired dopamine release and synaptic plasticity in the striatum of PINK1-deficient mice. Proc Natl Acad Sci U S A 104, 11441-11446.

[70] Gautier CA, Kitada T, Shen J (2008) Loss of PINK1 causes mitochondrial functional defects and increased sensitivity to oxidative stress. Proc Natl Acad Sci U S A 105, 11364-11369.

[71] Morais VA, Verstreken P, Roethig A, Smet J, Snellinx A, Vanbrabant M, Haddad D, Frezza C, Mandemakers W, VogtWeisenhorn D, Van Coster R, Wurst W, Scorrano L, De Strooper B (2009) Parkinson's disease mutations in PINK1 result in decreased Complex I activity and deficient synaptic function. EMBO Mol Med 1, 99-111.

[72] Petit A, Kawarai T, Paitel E, Sanjo N, Maj M, Scheid M, Chen F, Gu Y, Hasegawa H, Salehi-Rad S, Wang L, Rogaeva E, Fraser P, Robinson B, St George-Hyslop P, Tandon A (2005) Wild-type PINK1 prevents basal and induced neuronal apoptosis, a protective effect abrogated by Parkinson disease-related mutations. J Biol Chem 280, 34025-34032.

[73] Lin W, Kang UJ (2008) Characterization of PINK1 processing, stability, and subcellular localization. J Neurochem 106, 464474.

[74] Pridgeon JW, Olzmann JA, Chin LS, Li L (2007) PINK1 Protects against Oxidative Stress by Phosphorylating Mitochondrial Chaperone TRAP1. PLoS Biol 5, e172.

[75] Plun-Favreau H, Klupsch K, Moisoi N, Gandhi S, Kjaer S, Frith D, Harvey K, Deas E, Harvey RJ, McDonald N, Wood NW, Martins LM, Downward J (2007) The mitochondrial protease HtrA2 is regulated by Parkinson's disease-associated kinase PINK1. Nat Cell Biol 9, 1243-1252.

[76] Kim Y, Park J, Kim S, Song S, Kwon SK, Lee SH, Kitada T, Kim JM, Chung J (2008) PINK1 controls mitochondrial localization of Parkin through direct phosphorylation. Biochem Biophys Res Commun 377, 975-980.

[77] Weihofen A, Ostaszewski B, Minami Y, Selkoe DJ (2008) Pink1 Parkinson mutations, the Cdc37/Hsp90 chaperones and Parkin all influence the maturation or subcellular distribution of Pink1. Hum Mol Genet 17, 602-616.

[78] Moriwaki Y, Kim YJ, Ido Y, Misawa H, Kawashima K, Endo S, Takahashi R (2008) L347P PINK1 mutant that fails to bind to Hsp90/Cdc37 chaperones is rapidly degraded in a proteasomedependent manner. Neurosci Res 61, 43-48.

[79] Yang Y, Ouyang Y, Yang L, Beal MF, McQuibban A, Vogel H, Lu B (2008) Pink1 regulates mitochondrial dynamics through interaction with the fission/fusion machinery. Proc Natl Acad
Sci U S A 105, 7070-7075.

[80] Deng H, Dodson MW, Huang H, Guo M (2008) The Parkinson's disease genes pink1 and parkin promote mitochondrial fission and/or inhibit fusion in Drosophila. Proc Natl Acad Sci U S A 105, 14503-14508.

[81] Yoon Y, Krueger EW, Oswald BJ, McNiven MA (2003) The mitochondrial protein $\mathrm{hFis} 1$ regulates mitochondrial fission in mammalian cells through an interaction with the dynamin-like protein DLP1. Mol Cell Biol 23, 5409-5420.

82] Marongiu R, Spencer B, Crews L, Adame A, Patrick C, Trejo M, Dallapiccola B, Valente EM, Masliah E (2009) Mutant Pink1 induces mitochondrial dysfunction in a neuronal cell model of Parkinson's disease by disturbing calcium flux. $J$ Neurochem 108, 1561-1574.

[83] Irwin WA, Bergamin N, Sabatelli P, Reggiani C, Megighian A, Merlini L, Braghetta P, Columbaro M, Volpin D, Bressan GM, Bernardi P, Bonaldo P (2003) Mitochondrial dysfunction and apoptosis in myopathic mice with collagen VI deficiency. Nat Genet 35, 367-371.

[84] Piccoli C, Sardanelli A, Scrima R, Ripoli M, Quarato G, D'Aprile A, Bellomo F, Scacco S, De Michele G, Filla A, Iuso A, Boffoli D, Capitanio N, Papa S (2008) Mitochondrial respiratory dysfunction in familiar parkinsonism associated with PINK1 mutation. Neurochem Res 33, 2565-2574.

[85] Anichtchik O, Diekmann H, Fleming A, Roach A, Goldsmith P, Rubinsztein DC (2008) Loss of PINK1 function affects development and results in neurodegeneration in zebrafish. $J$ Neurosci 28, 8199-8207.

[86] Shimura H, Hattori N, Kubo S, Mizuno Y, Asakawa S, Minoshima S, Shimizu N, Iwai K, Chiba T, Tanaka K, Suzuki T (2000) Familial Parkinson disease gene product, parkin, is a ubiquitin-protein ligase. Nat Genet 25, 302-305.

[87] Palacino JJ, Sagi D, Goldberg MS, Krauss S, Motz C, Wacker M, Klose J, Shen J (2004) Mitochondrial dysfunction and oxidative damage in parkin-deficient mice. J Biol Chem $\mathbf{2 7 9}$, 18614-18622.

[88] Greene JC, Whitworth AJ, Kuo I, Andrews LA, Feany MB, Pallanck LJ (2003) Mitochondrial pathology and apoptotic muscle degeneration in Drosophila parkin mutants. Proc Natl Acad Sci U S A 100, 4078-4083.

[89] Pesah Y, Pham T, Burgess H, Middlebrooks B, Verstreken P, Zhou Y, Harding M, Bellen H, Mardon G (2004) Drosophila parkin mutants have decreased mass and cell size and increased sensitivity to oxygen radical stress. Development 131, 21832194.

[90] Jiang H, Ren Y, Zhao J, Feng J (2004) Parkin protects human dopaminergic neuroblastoma cells against dopamine-induced apoptosis. Hum Mol Genet 13, 1745-1754.

[91] Kuroda Y, Mitsui T, Kunishige M, Shono M, Akaike M, Azuma H, Matsumoto T (2006) Parkin enhances mitochondrial biogenesis in proliferating cells. Hum Mol Genet 15, 883-895.

[92] Darios F, Corti O, Lucking CB, Hampe C, Muriel MP, Abbas N, Gu WJ, Hirsch EC, Rooney T, Ruberg M, Brice A (2003) Parkin prevents mitochondrial swelling and cytochrome $\mathrm{c}$ release in mitochondria-dependent cell death. Hum Mol Genet 12, 517-526.

[93] Narendra D, Tanaka A, Suen DF, Youle RJ (2008) Parkin is recruited selectively to impaired mitochondria and promotes their autophagy. J Cell Biol 183, 795-803.

[94] Vives-Bauza C, Zhou C, Huang Y, Cui M, de Vries RL, Kim J, May J, Tocilescu MA, Liu W, Ko HS, Magrane J, Moore DJ, Dawson VL, Grailhe R, Dawson TM, Li C, Tieu K, Przedborski S PINK1-dependent recruitment of Parkin to mitochondria in mitophagy. Proc Natl Acad Sci U S A 107, 378-383. 